of attacking other regions than the motor part of the cerebral cortex, and that the motor area is not exclusively selective.

CASE 6.-The patient was a woman, aged 53 years. I first saw her in October, 1900, when she had suffered from gastric symptoms for eight months and pain and vomiting with loss of flesh. On examination I found extreme dilatation of the stomach reaching downwards to the hypogastrium, with marked peristaltic action from left to right on stimulating the stomach to contract. There was a hard, square, nodular tumour over the pylorus which was tender on pressure. iShe vomited enormous quantities of thick fluid daily or on alternate days, with ease to her pain. There was advanced malignant disease of the pylorus. She held her own until Dec. 20th, when I was called urgently to see her and found her comatose. The condition was peculiarly interesting. "The face, hands, arms, and body in general were of a dark ired colour with a bluish tinge. The hands were in the position characteristic of tetany. There was slight flexion of the wrists, but the fingers were extended at all joints and were opposed to each other. 'The feet were similarly affected, reach foot being extended with the toes flexed into the soles. The pupils did not react to light and the conjunctival reflex was absent. She had had two convulsive attacks previously to my seeing her, and she had one in my presence in which she became livid and after which the colour became dark red as before. The convulsions were chiefly facial, with twitchings of the arms. There was incontinence of urine. During and after the eclampsia there was some tetanic spasm of the jaws, but it could easily be overcome. The eyes were closed and on raising the lids $I$ found that there was divergent strabismus. There was no opisthotonos or any approach to it and the legs were not affected by the convulsions. She had another convulsive attack after I had seen her. She died the next day. The coma lasted to the end A fatal result during tetany must be of rare occurrence. A peculiar feature about the cortical irritation was, that though bilaterally the leg centres are so close together, they were not affected by the convulsions, which emanated chiefly from the centres for the facial and ocular muscles and the arms and hands. The cortical discharges apparently did not spread upwards or across by the callosal fibres.

Enfield.

CASE OF MULTIPLE EPITHELIOMA OF THE TONGUE IN A WOMAN, AGED TWENTY-FIVE YEARS, RESULTING IN SPONTANEOUS AMPUTATION OF THE GREATER PART OF THE ORGAN.

BY 'T. E. HAYWARD, M.B. LOND., F.R.C.S. ExG., AND

R. G. HENDERSON, M.A., M.B., Ch.B. ABerd,

THE following case presents so many points of interest that we feel it ought to be put on record. As the patient only came under our notice in the later months of the disease we are unable to vouch for the early history of the case, but the facts as gathered from herself and friends are as follows.

About the beginning of 1900 or the end of the previous year the patient, then about $24 \frac{1}{2}$ years of age, noticed a blister on the left border of the tongue opposite the molar teeth. The blister was irritated by the adjacent tooth and broke, a small sore resulting which was very painful. For some months, however, she paid little attention to this and in the meantime, having become pregnant, medical advice was further postponed till after the birth of the child. She then consulted a medical man who advised removal of several teeth and this was done in a provincial infirmary last December. At the same time a portion of the ulcer, which she describes as being "only a small opening then," was removed and examined and was stated to be "not cancer." She was given a mouth-wash but no mellicine. The ulcer, howerer, now got rapidly larger and after a stav of three weeks in the institution she went out feeling rather worse than before. On March 23 rd of the present rear the patient came uncler our notice for the first time suffering from severe arterial bleeding from the mouth. This proceeded from a hnge ulcer of the tongue about the middle of the left border or rather farther back. The ulcer appearerl as a deep cavern about half an inch in diameter at the surface and an inch or more in depth, its direction being down and in towards the hyoid bone. The base could not be seen on account of it, great depth but conld be felt with the finger and from the base the bleeding appeared to proceed. The walls of the ulcer were even, firm, but not indurated, while the margin was clean cut, perhaps a little raised, but not indurated or everted. 'The bleeding was stopped by packing with gauze moistened with tmpentine and perchloride of iron.

The diagnosis at this stage was difficult. The patient was a young married woman, aged 25 years, the mother of thret healthy children and of good previous health, although now rather pale and poorly nourished. She had never had : miscarriage or anything to indicate svphilitic infection. Her family history was excellent. Her parents and grandparent. were still alive and were known to us as particularly healthy people. A remote family history of cancer was, however, obtained: (1) the patient's great-grandfather (grandfather'; father) died from cancer; and (2) a nephew of her grandmother died from cancer of the lip, aged about 50 years, attributed to the use of a clay pipe. A slight taint would, therefore, appear to be present in both grandparents which we mention for what it is worth. The pain from the ulcer was only moderate; the discharge was slight and foetid The jaw appeared to be slightly swollen on that side and : small gland was felt under it. 'The diagnosis we considered uncertain, but we put the patient on anti-svphilitic and tonic treatment, together with an antiseptic alkaline mouth-wash On March 25th the patient was suffering intense pain on the right side of the tongue, especially on attempts to swallow: this had been present, more or less, for two days, but wa now much worse. She attributed it to the manipulation in packing the ulcer two days before when the tongue was pushed to the right side and irritated by a sharp tooth. T'hi we found to be the case. There was an acute inflammatory swelling of the size of a large pea, very red and tender, on the border of the tongue, while the adjacent tooth had a shary ragged edge. This tooth was removed on the following day, together with one on the opposite side which it was thought might irritate the ulcer. On the 29th it was noted that the ulcer was getting smaller. The inflammatory swelling on the right side was also rather smaller and the pain was almost gone. The swelling was paler in colour also, and at one part the pale, semi-translucent appearance, together with the increased hardness, suggesterl malignancy. On April 1st the nlcer was noted as getting smaller, but the walls appeared more roughly irregular. The tongue moved as if it would break across if pushed to the right. The swelling on the right sicle had not disappeared, but was now pale and hard and had begun to ulcerate on the summit. On the 19th the swelling on the right side had ulcerated deeply, so that there was now a cleft extending across the right half of the tongue towards the original ulcer. Behind and in front the cleft was bounded by a raised hard ridge of clearly malignant character. On this day also the patient conplained of pain in the floor of the mouth under the fore part of the tongue. She had felt it slightly for a day or two. On examination a narrow transverse ulcer was found in the region of the frænum. This ulcer was malignant in character but quite distinct from either of the other two. The disease now made rapid progress. The cleft on the right sirle extended across to join the large ulcer on the left, so that the tongue appeared to be divided into two parts by a deep ulcerating trench running horizontally across the dorsum about its middle. The possibility of relief by operation had been suggested to the patient some time before but was not urged as we considered neither the local nor general conclitions favourable. At our request, however, she entered the Liverpool Royal Infirmary on April 27th under the care of $\mathrm{Mr}$. F. 'I. Paul, but operation was considered undesirable and she returned home in a few days. On May 4th the anterior portion of the tongue became detached, a result we harl expected for some time. There was no bleeding. 'The patient, who had felt it getting loose for a day or two, simply lifted it out of the mouth without any severance of tissue. The detached portion was received the following dav. It measured one inch long from tip to base and one and a quarter inches broad at the base which was slightly oblique. The under surface was nlcerated. The extreme tip had become black from commencing ganorene. The floor of the mouth now presented in front a dirty grey nodular area, limited behind by an ulcerating overhanging wall which reprecented 
the free edge of the root of the tonguc. The increased pain now caller for large doses of opium, and this for a time harl the effect of slightly improving the patient's general condition, which was very miserable, and also, we feel sure, of checking to some extent the local disease. Life dragged on till June 15th, when she succumbed to the extreme exhanstion from pain, lack of nourishment, and the effects of occasional large hæmorrhages. Her age at death was 26 years and one month. A few days before her death the local condition was as follows. A deep excavation ran alongside the left ramus of the jaw, extending back to involve the fauces and tonsil. The bone itself was carions and thickened on the same side. On the right sirle the ulceration was less deep. The floor of the mouth was flat and firmly nodular in front, while behind the root of the tongue was represented by a low monnd of tissne with a median depression permitting a full view of the pharynx. The general emaciation was extreme. The total duration of the illness was about 18 months. Although the clinical features had for long left no doubt as to the diagnosis a portion of tissue was sent for examination to the Clinical Research Association who reported: "These sections show a typical squamous-celled epithelioma of the tongue which has already invaded the muscular tissue. There is no evidence of any previous syphilitic lesion. The age and sex of this patient are very exceptional."

Remarks. - We have confined our account chiefly to the local features of the case as these were of the most peculiar interest. The pain, salivation, difficulties of feeding, and general distress were such as occur in every case of advanced cancer of the tongue. A few points, however, call for special remark. First, as to age and sex. Cancer of the tongue is decidedly rare under 30 years of age. Butlin ${ }^{1}$ refers to the few recorded cases, three in males and three in females. In the present case the trouble began about the age of $24 \frac{1}{2}$ years and lasted about 18 months; but we are doubtful whether it was malignant from the beginning. It is also a curious fact that whereas of cases of cancer of the tongue in general only about 15 per cent. are women, yet when the disease occur's under the age of 30 years it affects the sexes equally. 'Then as to the multiple character of the lesions. We had here three distinct centre of malignant ulceration : first, the original large ulcer secondly, the acute inflammatory swelling on the right border of the tongue, which from day to day we watched gradually assume malignant characters and from which the fragment for microscopical examination was taken; and thirdly, that beginning on the frænum and extending backwards. Each of them was clinically malignant, although a portion of one only was submitted to microscopical examination. Butlin ${ }^{2}$ states that a good number of donble epitheliomas have been recorded, but that the number two has not been exceeded. We think in the present case that there were three and to a certain extent we can explain their occurrence. Assuming, as we must, that in this patient there existed some overwhelming tendency to cancerons disease, we would expect it, like other pathological conditions, to attack spots of lowered tissue vitality. This was clearly so on the right border of the tongue where a' sharp tooth cansed an acute inflammatory swelling-a common enough occurrence; however, although the cause was removed the effect did not disappear bnt became gradually tranformed into a malignant tumour. So with regard to the fromum. The constant soaking in an extremely irritating and possibly infective discharge would undonbtedly lower its vitality and hence it succumbed. Thirdly, the combined effect of those lesions in producing a spontaneous amputation of the greater part of the tongne must be, we imagine, a very unusual accurrence. We have not seen a description of anything similar. The way in which it was brought about was very simple. The two ulcers on the opposite borders of the tongue gratually united across the dorsum and then formed a deep vertical trench across the tongue, which was met by the third nlcer extending backwards from the frænum along the floor of the mouth.

Finally. as to the treatment little need be said. Antisyphilitic measures, although they appeared to bring about improvement at first, were discarded after a few weeks. Fotor was combated by an antiseptic mouth-wash. Pain was allayed by a paint of $\beta$-encaine locally and opium internally. We believe that the free use of opiun in the later stages prolonged the life of this patient by about two months. Havdock, Laneashire.

1 Butlin and Spencer: Diseases of the Tongue, second edition, p. 312.

\section{A CASE OF EXTENSIVE ENTERECTOMY.}

\section{BY ARTHUR E. BARKER, F.R.C.S. ENG.,}

PROFESSOR OF THE PRINCIPLFS AND PRACIICE UF SURGFRY A' UNIVERSITY COLLEKF, AXD SURGEON TO UNITERSITY COLLEGE HOSPITAL, LONDON.

THE following case illustrates a very dangerous sequel to an ordinary simple strangulated femoral hernia operated on in the usnal way and its cure by extensive enterectomy. It also suggests some questions bearing upon the general treatment of cases of severe strangulation without actual gangrene.

The patient, a married woman, aged 39 years, was admitted into University College Hospital on July 1st, 1900. Her personal and family history was gond. She had suffered from a right femoral hernia of moderate size for four or five months which had come down during a bad fit of coughing. It gave but little pain or other trouble and always returned on lying down. On the afternoon of June 30th, some 18 hours before admission, the hernia came down while the patient was walking in the garden and. caused great pain all over the abdomen and the back whick was continuous. At 9 P.M. she romited and at intervals during the night. She took some castor oil, but it returned at once. On one occasion the vomit contained a little dark blood. The next morning (July 1st) she was admitted and I operated at once. The usual incision was made and when the sac was openerl a good deal of fluid of high colour and foul smell escaper. The gut was dark, congested, and œdematous, but it retained its lustre. Both sac and gut were now carefully washed before the constriction was divided. The bowel was then drawn down and examined for further damage, but none was found. As the cedema of the loop soon began to disappear when released and as the circulation seemed good it was washed. dried, and reduced into the abdomen. The usual radical cure was then done and the wound in the soft parts was closed without drainage. Recovery was rapid and uneventful except for flatulence. The bowels acted unaided on the sixth day and subsequently. There was no sickness after the operation but there was some pain in the abrlomen.

The stitches in the skin wound were removed on the tenth day, when perfect primary union was found. The patient left the hospital perfectly well on the sixteenth day for Brixton. Some weeks later I heard from her medical attendant, Dr. Horden, that she had a severe attack of intestinal obstruction with great pain on vomiting. This passed off, however, under his skilful treatment with opium enemata and fomentations and she was able towards the end of August to return home to Cornwall. But before doing so she called at the hospital to show herself and she then seemed to be in excellent condition. At the beginning of October, 1900, I har a letter from her medical attendant, Dr. F. Hichens of Redruth, to say that on Sept. 9th she had been attacked again suddenly with intestinal obstruction in a very severe form with great pain starting in the right groin and spreading all over the abdomen, with vomiting and distension, so that he feared for her life, so great was the collapse and so extensive the peritonitis. His very thoughtful treatment was, however, followed by recovery. His object in writing was to suggest exploration, of the abdomen as it seemed beyond doubt that there must be a kink or adhesion, or both, abont the point of the bowel which was originally involved in the hernia. The patient returned to London with this object in view and she was re-admitted on Oct. 13th, 1900. She now appeared to be in good health, but she gave a history of great constipation. alternating with diarrhoea ever since the first operation, combined with much flatulence. Since the last attack on Sept. 9th she had only to complain of irregular bowels, flatulence, and irreoular and painful spasms on the right side of the abdomen. On examination there was no trace of the return of the hernia at the seat of the first operation and no tenderness was there. The abdomen was generally soft, but there was some tenderness in the right iliac fossa on deep pressure and there were some indefinite thickening and resisttance as well. Nothing abnormal was found otherwise in the abdomen.

1 A paper read before the Medical Society of London on April 22nd, 